\title{
Economic valuation of informal care provided to people after a myocardial infarction in France
}

\author{
Hugo Rabier ${ }^{1,2^{*}}$ (D), Hassan Serrier ${ }^{1,3}$, Anne-Marie Schott ${ }^{1,2}$, Nathan Mewton ${ }^{4}$, Michel Ovize ${ }^{4}$, Norbert Nighoghossian ${ }^{5,6}$, \\ Antoine Duclos ${ }^{1,2}$ and Cyrille Colin ${ }^{1,2}$
}

\begin{abstract}
Background: The aim of this study was to estimate the mean cost per caregiver of informal care during the first year after myocardial infarction event in France.

Methods: We used the Handicap-Santé French survey carried out in 2008 to obtain data about MI survivors and their caregivers. After obtaining the total number of informal care hours provided by caregiver during the first year after Ml event, we estimated the value of informal care using the proxy good method and the contingent valuation method.

Results: For MI people receiving informal care, an annual mean cost was estimated at $€ 12,404(S D=13,012)$ with the proxy good method and $€ 12,798(S D=13,425)$ with the contingent valuation method per caregiver during the first year after myocardial infarction event.
\end{abstract}

Conclusions: The present study suggests that informal care should be included more widely in economic evaluations in order not to underestimate the cost of diseases which induce disability.

Keywords: Informal care, Myocardial infarction, Contingent valuation method, Willingness to pay, Cost, France

\section{Background}

Outcomes of health economic evaluations are one of the criteria used by decision-makers for market access of medical devices and new drugs. Economic evaluations are required for all new drugs in Australia, Hungary, New Zealand and Sweden; upon request one year after launch in Germany; and for specific drugs and devices in England and Wales [1]. In France, the use of health economic evaluations in the decision-making process is more recent. Since 2013, a health economic evaluation is requested by the French national evaluation agency named Haute Autorité de Santé (HAS) only for an

\footnotetext{
* Correspondence: hugo.rabier@chu-lyon.fr

'Hospices Civils de Lyon, Pôle de Santé Publique, Service d'Evaluation Economique en Santé, 162, avenue Lacassagne - Bâtiment A, 69424, Cedex 03 Lyon, France

Université de Lyon, Université Claude Bernard Lyon, Université

Saint-Etienne, HESPER EA 7425 F-69008 Lyon, F-42023 Saint-Etienne, Lyon,

France

Full list of author information is available at the end of the article
}

innovative and expensive drug or medical device [2]. From the HAS perspective, innovative products are defined as those for which the manufacturers claim a moderate to major improvement of the clinical benefit compared to that provided by existing treatments. Expensive products refers to a product which have a significant impact on the statutory national health insurance expenditures or an impact on the organization of care, professional practices or patient care conditions. In parallel, the HAS published a methodological guide for the economic evaluation [3] in which it is stipulated that if the viewpoint adopted for the evaluation was societal, informal care cost should be included. Informal care represents the care provided by family members, close relatives, friends, or neighbors who are not a professional caregiver and not trained to provide care, and without monetary compensation [4].

Costs of informal care can represent a significant proportion of the total cost induced by the disease, especially for chronic diseases. Even if several valuation methods of

(C) The Author(s). 2019 Open Access This article is distributed under the terms of the Creative Commons Attribution 4.0 International License (http://creativecommons.org/licenses/by/4.0/), which permits unrestricted use, distribution, and 
informal care exist, as the proxy good (PG) method, the opportunity cost method and the contingent valuation (CV) method, these costs are not always taken into account in the economic evaluations of chronic diseases and more rarely for acute illness like myocardial infarction (MI). Many international and European studies report that informal care represents a major economic impact and a real burden for caregivers associated with chronic diseases like dementia or cancers [5-9]. This is not really a surprising finding for chronic diseases, but may be less suspected for acute illness such as acute coronary syndrome although there are long-term effects in part due to chronic complications (namely congestive heart failure). Acute coronary syndrome refers to a spectrum of clinical presentations ranging from those for ST-segment elevation MI to presentations found in non-ST-segment elevation MI or in unstable angina [10]. In France, informal care valuation studies are mainly focused on Alzheimer's Diseases and disabled elderly people [11-14].

MI represents the main cause of mortality among coronary heart disease patients in Europe $[15,16]$, and in France, the incidence of MI is estimated to be around 120,000 cases every year [17]. MI can cause difficulties in performing realize activities of daily living (ADLs) and instrumental activities of daily living (IADLs), that may involve the need of an informal caregiver [18]. However, no evaluation of the cost of informal care in MI has ever been conducted. The absence of informal care cost in economic evaluations can be explained by the fact that this is not a chronic disease but can also be explained by the small amount of data available or studies carried out from a societal perspective. Moreover, inclusion of informal care in economic evaluation induces methodological issues because caregivers can meet difficulties to quantify hours of informal care provided. When caregiver and care receiver live together, the caregiver can overestimate the informal care duration if he fails to distinguish additional housework provided to assisted person and "normal" daily home activities [19].

In spite of the recommendations from the methodological guide for the economic evaluation [3] to include cost of informal care in medico-economic evaluation, few studies provided these data and only concern chronic diseases. We propose to estimate the informal care costs for acute illness taking the case of MI as an example.

The main objective of the present study was to estimate the mean cost per caregiver of informal care during the first year after an MI event in France because MI is associated with significant increases in functional disability at short-term [18] and the majority of second events occur in the first year following the MI event [20]. To do this, we used the CV and the PG methods based on data provided by the Handicap-Santé survey $[21,22]$. We also realized a systematic review to estimate an approximate overall mean cost of MI management during the first year in order to quantify the relative weight of informal care.

\section{Methods}

\section{Data source}

Data was collected from the prospective 2008 Health and disabilities households survey (Enquête HandicapSanté), carried out in the French general population by the French National Institute of Statistics and Economic Studies and the Department of Research, Studies, Evaluation and Statistics. The first part of this survey, named Handicap-Santé, volet Ménages (HSM) [21], was conducted in ordinary households and collected socio-demographic, economic and health information from approximately 30, 000 participants. It examined the consequences of health problems on functional limitations, care-seeking (professional and informal), professional and daily activities, and degree of dependence. Degree of dependency was determined in the survey according to the Katz Index of Independence in ADLs (bathing, dressing, go and using the toilet, getting in and out of bed and enter then leave his seat, incontinence and feeding) [23]. This instrument is used to assess functional status as a measurement of ability to perform activities of daily living activities. People were scored for dependence in each of six activities. A score of 6 indicates that individual was able to make the 6 ADLs, and below six an impairment to realize at least one ADL. In the present study, care receivers with a score equal to 6 were classified as "autonomous to realize the 6 ADLs" and below 6 , individuals were classified in the "not able to realize at least one ADL" category. The second part of the survey, Handicap-Santé, volet Aidants informels (HSA) [22], was based on telephone or face-to-face interviews with approximately 5000 informal caregivers of the people interviewed in the first part of the survey. Information was collected about personal characteristics, professional activity, social environment, description of care provided (type of activity and number of hours per week) and impact of provided care on family, professional and social environment.

We selected in the HSM survey, people survivors of MI less than 12 months before the interview and who received informal care. Then, we linked care-receivers with their caregiver who answered to the HSA survey.

\section{Economic valuation}

We estimated the economic value of informal care in two steps. First, we used the number of informal care hours provided per week and per caregiver stated in the HSA survey. Caregivers may encounter difficulties distinguishing informal care from daily "normal" home activities when they live with the assisted person and can overestimate the duration of informal care. To avoid an 
overestimation, we computed two estimates of the value of informal care: one in which the stated duration of informal care was restricted to $10 \mathrm{~h}$ ("restricted scenario"), and the other without restriction ("unrestricted scenario"). We chose a maximum of $10 \mathrm{~h}$ because $90.6 \%$ of caregivers stated an informal care duration inferior or equal to $10 \mathrm{~h}$ per day.

Then, we valued care time using the PG and the CV methods. The PG is a revealed preference method which values informal care time at the labour price of a market substitute by applying the market wage rate of a close substitute. Assuming that informal and formal care are perfect substitutes, the wage rate of a professional caregiver may be used to value informal hours [19]. However, care hours should be valued according to the task carried out, care at the market wage of a home-care nurse and housework tasks at the market wage of housekeeper. Care hours can also be valued using the French legal minimum gross hourly wage [13] set at $€ 9,76$ on 1 January 2017 [24]. We valued care hours using the minimum hourly wage because the HSA survey data cannot determine precisely the number of hours according to the type of care performed by caregivers. We assumed that the minimum hourly wage is near to home-care nurse and housekeeper mean wage rate because the qualification level of person working in the home personal services care sector is low [25].

The CV is used to obtain the monetary value per hour of informal care from the perspective of the informal caregiver on the basis of stated preferences. The caregiver assesses the maximum amount of money willing to pay (WTP) to be replaced for one hour of informal care. This method allows us to capture all relevant aspects of informal care due to its sensitivity to the different situations informal caregivers faced with, and it reflects their preferences [12]. The latter was collected in the HSA survey through the following open question regarding their WTP to be substituted for one additional hour of caregiving:

'Suppose you have the opportunity to be replaced for one hour of care in the week. What is the maximum amount would you be willing to pay for this hour of care? Mind that this amount corresponds to a reduction of your budget'.

If caregivers met difficulties to answer, a second question proposing a fixed payment scheme:

'To help you, I am going to show you a table with different values. You could start to remove all amounts of which you are sure do not pay. Then, select all amounts whose you are sure to pay. Lastly, select the maximum amount would you be willing to pay'.
Some caregivers may find it unethical to indicate a monetary value and it may lead to protest answer illustrated by a willingness to pay stated equal to "0" or caregivers could refuse to give a WTP value to the first question. WTP value equals to zero was considered as "protest answer" only when caregiver gave a justification. We noted the number of "protest answers" but we integrated WTP value equal to " 0 " in the analysis.

Informal care cost estimates were presented in 2017 euros. WTP values stated were inflated to 2017 euros using the appropriate Consumer Price Index published by the French National Institute of Statistics and Economic Studies [26].

\section{Results}

\section{Study sample}

We selected 798 people survivors of MI in HSM survey. Among this selection, the sample was restricted to 236 survivors of MI less than 12 months before the survey. Then, we retained individuals who received care by one or several informal caregivers $(n=145)$. Among these individuals, we selected MI survivors for whom caregivers who responded to the HSA survey $(n=64)$. Our final sample was 52 care receivers and their 64 caregivers (Fig. 1).

Table 1 shows characteristics of care receivers and their caregivers. Average age of care receivers is 71.0 years old and the distribution of genders is balanced (women 48.1\%). Forty four percent of care receivers are single and $70.3 \%$ are « autonomous » to perform activities of daily living according to the Katz index. Care receivers autonomous to realize the 6 ADLs received mainly care as "management organization/medical appointment scheduling" (80.7\%), "medication management" (75.0\%) and "moral support" (60.5\%). Whereas care receivers with an impairment to realize at least one ADL received care as "toileting" (49.1\%), "bathing" (47.2\%), "dressing" (60.0\%) and "moral support" (75.3\%). Caregivers are mainly partner (50.0\%) and son or daughter (37.5\%), and more than half lives with their care recipient (73.1\%).

\section{Economic value of informal care}

The average WTP stated by caregivers to be replaced for one hour of care is $€ 10.7$ ( $\mathrm{SD}=6.83$; median $=10$; IQR [5-15]; range [0-25]). 8 caregivers stated a WTP value equal to "0". Among these null WTP, 3 caregivers expressed a disagreement ("it is my duty" or said "I want to do it".) and are considered as "protest answers" (Table 1).

The average annual value of informal care per caregiver obtained using the CV method is $€ 12,798$ (no restriction scenario) for a daily average duration of informal care of $3.5 \mathrm{~h}$ (Table 2). The average value of informal care for autonomous people is substantially less than dependent people: respectively $€ 10,228$ versus $€ 20,270$ for the no restriction scenario and $€ 10,086$ versus $€ 17,169$ for the 


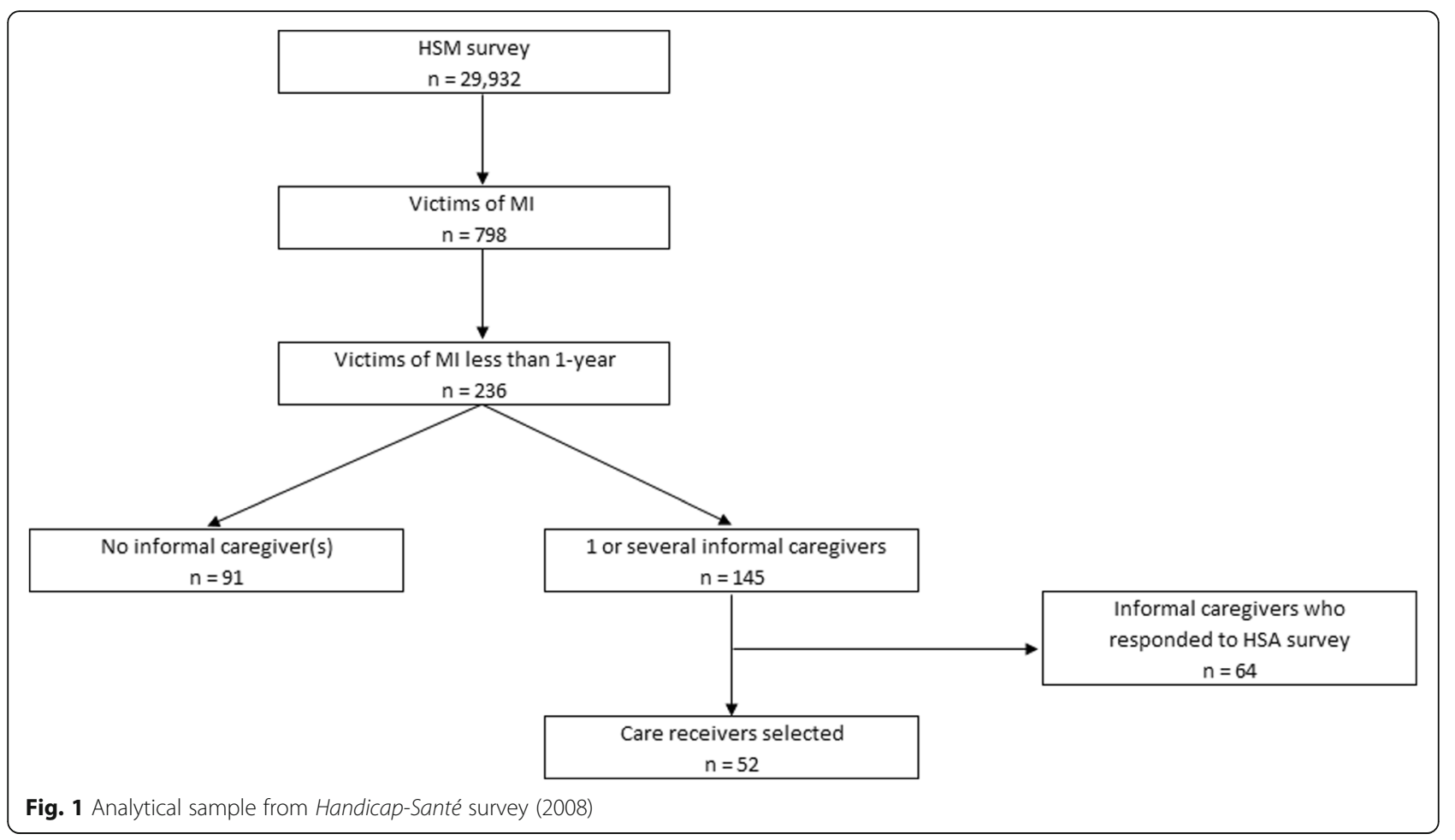

restriction scenario. A sensitivity analysis with the "protest zeros" data was carried out. The "protest zeros" values were replaced by the mean WTP of similar caregivers according to the Index Katz score of their care receivers, if they lived together and if they had a work activity. An average annual value of informal care per caregiver at $€ 14$, 062 (no restriction scenario) and $€ 13,061$ (restriction scenario) was obtained.

The average annual value of informal care per caregiver obtained using the PG method is $€ 12,404$ (no restriction scenario). The average value of informal care for autonomous people is substantially less than dependent people: respectively $€ 10,337$ versus $€ 21,099$ for the no restriction scenario and $€ 10,233$ versus $€ 17,776$ for the restriction scenario.

\section{Discussion}

Among MI survivors receiving care provided by informal caregiver, we estimated a mean cost per caregiver of informal care at $€ 12,798$ using the CV method and $€ 12,404$ using the PG method. The findings further suggest that informal care cost cannot be considered negligible in MI and underline the importance of incorporating informal care costs in economic evaluations to assist policy-makers in the allocation of limited resources for healthcare provision.

A study estimated the informal care cost for patients with Alzheimer's disease at $€ 11,269$ per year for a mild Alzheimer's Disease severity and $€ 28,883$ for a moderate to severely Alzheimer Disease severity with the PG method in France [27]; with the opportunity cost method, cost of informal care was estimated to be $€ 15$, 706 and $€ 39,864$ per year, respectively. Another study valued informal care associated with dementia in Central Europe and obtained a mean duration of informal care reported to be $31.23 \mathrm{~h}$ per week corresponding to an average annual cost of informal care estimated at $€ 21$, 126 [8]. Our lower cost estimation of informal care is not surprising in comparison with a chronic disease, but according to the same study, the average annual cost of informal care associated with stroke was estimated at $€ 6576$ with a mean duration of $23.98 \mathrm{~h}$ per week. It can be explained because the latter estimated a mean of informal care with several study results taking into account stroke events diagnosed more than one year. Whereas we only focused on during the first year after MI, the majority of second event occurring in the first year [20]. In consequence, MI survivors required more care in the first year than long-term. These comparisons shows our results are consistent with the literature and that informal care cost could vary according to the valuation method used, the level of dependence, but also country studied [8].

To value informal care cost, we used the PG and CV methods. Although the two valuation methods were based on different shadow prices, overall cost estimations did not vary significantly. Despite the fact that the $\mathrm{CV}$ method captures the preference heterogeneity of caregivers, several studies showed that caregivers have 
Table 1 Characteristics of care receivers and their caregivers, care receivers who refused to respond

\begin{tabular}{|c|c|c|c|}
\hline Characteristics (\%) & Informal caregivers $(n=64)$ & Care receivers $(n=52)$ & $\begin{array}{l}\text { Care receivers with caregivers who } \\
\text { refused to respond }(n=93)\end{array}$ \\
\hline Age (mean) & 54.9 & 71.0 & 72.4 \\
\hline Female & 71.9 & 48.1 & 37.6 \\
\hline Married/couple & 62.9 & 55.8 & 54.2 \\
\hline \multicolumn{4}{|l|}{ Relationship with care receiver } \\
\hline Partner & 50.0 & - & 48.7 \\
\hline Brother/sister & 6.2 & - & 5.1 \\
\hline Son/daughter & 37.5 & - & 40.0 \\
\hline Other family member & 3.1 & - & 3.6 \\
\hline Friend & 1.7 & - & 2.6 \\
\hline Cohabitation with care receiver & 73.1 & - & - \\
\hline \multicolumn{4}{|l|}{ Educational level } \\
\hline No degree/primary school & 48.4 & 73.1 & 76.0 \\
\hline Secondary school & 40.6 & 23.1 & 21.7 \\
\hline University degree & 6.2 & 3.8 & 2.3 \\
\hline Refusal & 4.8 & 0.0 & 0.0 \\
\hline \multicolumn{4}{|l|}{ Dependency } \\
\hline Autonomous & - & 70.3 & 72.3 \\
\hline Dependent & - & 29.7 & 27.7 \\
\hline Duration of care provided per day (hours) & 3.5 & - & - \\
\hline Autonomous & 2.9 & - & - \\
\hline Dependent & 4.9 & - & - \\
\hline WTP stated (euros) & 10.7 & - & - \\
\hline Autonomous & 9.6 & - & - \\
\hline Dependent & 11.2 & - & - \\
\hline
\end{tabular}

difficulty giving a WTP value on a hypothetical market. Hence, caregivers tented to refer to the value of one hour on the professional home care market [28] which could explain these similar estimations. Another valuation method exists: the opportunity cost method This method estimates the cost of informal care by using the market wage of the caregiver or of a home care service

Table 2 Average annual value of informal care per caregiver according to valuation method and dependency (2017 euros)

\begin{tabular}{|c|c|c|c|}
\hline & Autonomous (SD) & Dependent (SD) & Total (SD) \\
\hline \multicolumn{4}{|c|}{ Contingent Valuation Method } \\
\hline No restriction & $10,228(10,253)$ & $20,270(12,984)$ & $12,798(13,425)^{a}$ \\
\hline Restriction & $10,086(9872)$ & $17,169(12,171)$ & $11,888(11,848)^{b}$ \\
\hline \multicolumn{4}{|c|}{ Proxy Good Method } \\
\hline No restriction & $10,377(10,402)$ & $21,099(12,604)$ & $12,404(13,012)$ \\
\hline Restriction & $10,233(10,016)$ & $17,776(11,4604)$ & $11,522(10,643)$ \\
\hline
\end{tabular}

No restriction scenario: exact durations of care stated by caregivers. The mean is $3.5 \mathrm{~h}$ of informal care/day/caregiver

Restriction scenario: durations superior to $10 \mathrm{~h}$ were censored to a maximum of $10 \mathrm{~h}$ per day. The mean is $3.2 \mathrm{~h}$ of informal care/day/caregiver

${ }^{\mathrm{a}}$ Total (SD) including zero protest $=€ 11,921(13,528)$ only depending on the work and leisure time forgone to provide informal care and does not take into account the heterogeneity preferences of people [29]. Caregiver preferences are heterogeneous because they are affected by individual characteristics, caregivers do not reason only by duration of care provided and can give more importance to the type of care activities, the home distance with the care receivers or the frequency of care provided. The CV method captures heterogeneity preferences of caregivers via the WTP and follows the welfare theory based on individual preferences [30]. Moreover, to compare informal care cost in MI patients with other countries, the $\mathrm{CV}$ method could be used to give a representation of the informal care to be taken into account the specificities as the health systems and cultural aspects with the WTP. But, it is necessary to compare results of other studies with caution because results may have varied depending on the diseases studied, the level of dependency, the current policies and cultural differences between the countries concerned. For instance, in the Nordic countries and the Netherlands, aid policies for care receivers to employ a professional home care or a housekeeper is more 
widespread than in France, Germany, or England. The existence of a professional care can have an impact on the WTP stated by the caregiver [31]. Another alternative is to use the willingness to accept (WTA) in the CV method to capture caregivers' preferences. Several studies shown that WTA values for non-market goods are two to five times higher than the WTP values [32-34]. WTA is known to suffer from a bias due to the lack of budget constraint and to loss aversion [35]. Lastly, the National Oceanic and Atmospheric Administration (NOAA) Panel Report recommends the use of WTP in contingent valuation studies because the report claims that "respondents are more likely to exaggerate the compensation they would require than their willingness to pay [36].

Some limitations of the present study should be noted. The CV method contains a hypothetical bias because this method is only focused on monetary value. Caregivers may find it unethical to indicate a monetary value and it may lead to protest answer illustrated by a willingness to pay stated equal to "0" [14]. To consider protest answers, we might also have included an estimation without the WTP answer equal to zero when it is specified in comment that the caregiver do not want to pay to be substituted. But we choose the conservative assumption to avoid overestimation and carried out a sensitivity analysis substituting the "protest zeros" by the mean WTP of similar caregivers according to sociodemographic characteristics. On the other hand, as caregivers were not confronted with a real market; informal caregivers can have difficulties estimating a monetary value on the hypothetical market which could result in an under or over-estimation of the WTP.

The estimation of informal care is based on a restricted sample of 64 caregivers and important information about informal care is loss because 81 caregivers did not want to respond to the HSA survey. Care receivers linked with the caregivers who did not want to respond received $2.11 \mathrm{~h}$ per day on average. The Handicap-Santé survey dates back to 2008 and can represent a limitation because management (greater use of reperfusion therapy and recommended medications) and secondary treatments of MI have evolved over the last 10 years, resulting in significant improvements in outcomes [37]. These outcome improvements induce a modification of formal and informal care needs However, the Handicap-Santé survey is the sole database providing informal care data about MI survivors and individual estimations of the WTP for informal caregivers of MI survivors that allow us to use the CV method. The CV method is less frequently used because of the use of survey which are costly, complex and time-consuming.

Health economic evaluations are useful for decision makers particularly for pricing negotiation and reimbursement of health product. Krol et al. [38] recalculated Incremental cost-effectiveness ratios (ICERs) from studies including informal care and they showed that the inclusion of informal care may have an impact on costeffectiveness outcomes and may even exceed medical costs. In a study which analysed how the inclusion of social costs could change ICERs of economic evaluations of interventions for Alzheimer's disease. Among 55 economic evaluations identified in which both health care payer and societal perspectives were included, authors showed that in 3 of them, the new intervention became cost-effective when social costs were taken into account [39]. However, despite guidelines, informal care costs are not routinely considered in health economic evaluations.

Results suggest that informal care can represent a nonnegligible economic impact and should be included in economic evaluations not only for chronic diseases but also for acute illnesses in order not to underestimate the cost of diseases, which induce dependencies. Including informal care in economic evaluations allows reporting to the French decision-makers the role of caregivers, promoting their social recognition with the aim of considering an appropriate mixture of care in order to improve caregiver quality of life via introduction of measures, for instance, more flexibility to adapt working-time and respite home programmes.

\section{Conclusions}

Taken together, the present study provides a quantitative indication on the fact that informal care represents a significant economic impact for informal caregivers.

\section{Abbreviations \\ ADL: Activities of Daily Living; CV: Contingent Valuation; HAS: Haute Autorité de Santé; HSA: Handicap-Santé Aidants; HSM: Handicap-Santé Ménages; IADL: Instrumental Activities of Daily Living; ICER: Incremental Cost Effectiveness Ratio; MeSH: Medical Subject Headings; MI: Myocardial Infarction; NOAA: National Oceanic and Atmospheric Administration; PG: Proxy Good; PRISMA: Preferred Reporting Items for Systematic Reviews and Meta-Analyses; SD: Standard Deviation; WTA: Willingness To Accept; WTP: Willingness To Pay}

\section{Acknowledgments}

The authors wish to thank Philip Robinson (DRCl: Direction de la Recherche Clinique et de l'innovation, Hospices Civils de Lyon), for his help in editing the manuscript.

\section{Authors' contributions}

HR analyzed and interpreted data, realized literature review and was a major contributor in writing the manuscript; $\mathrm{HS}$ analysed data, co-written, realized literature review and revised manuscript; CC realized literature review and revised manuscript; $A M S, N M, M O, N N$ and $A D$ revised manuscript. All authors read and approved the final manuscript.

\section{Funding}

This work was supported by the RHU MARVELOUS (ANR-16-RHUS-0009) of I'Université Claude Bernard Lyon 1 (UCBL), within the program

"Investissements d'Avenir" operated by the French National Research Agency (ANR). The funding source had no role in the study design; in the collection, analysis and interpretation of data.

Availability of data and materials

The datasets used and/or analysed during the current study are available from the corresponding author on reasonable request. 


\section{Ethics approval and consent to participate}

Not applicable.

\section{Consent for publication}

Not applicable.

\section{Competing interests}

The authors declare that they have no competing interests.

\section{Author details}

${ }^{1}$ Hospices Civils de Lyon, Pôle de Santé Publique, Service d'Evaluation Economique en Santé, 162, avenue Lacassagne - Bâtiment A, 69424, Cedex 03 Lyon, France. ${ }^{2}$ Université de Lyon, Université Claude Bernard Lyon, Université Saint-Etienne, HESPER EA 7425 F-69008 Lyon, F-42023 Saint-Etienne, Lyon, France. ${ }^{3}$ Hospices Civils de Lyon, Cellule Innovation, Délégation à la Recherche Clinique et à l'Innovation, Lyon, France. ${ }^{4}$ Hospices Civils de Lyon, Groupement Hospitalier Est, Centre d'Investigation Clinique, INSERM 1407, Bron, France. ${ }^{5}$ Department of Neurology, Hospices Civils de Lyon, Université Lyon 1, Lyon, France. ${ }^{6}$ Department of Stroke Medicine, Hospices Civils de Lyon, Université Lyon 1, Lyon, France.

\section{Received: 29 June 2018 Accepted: 14 October 2019}

\section{Published online: 28 October 2019}

\section{References}

1. Kobelt G. Health Economics: An Introduction to Economic Evaluation [Internet]. 2013 [cited 2018 Feb 9] p. 7. (Office of Health Economics). Available from: https://www.ohe.org/publications/health-economicsintroduction-economic-evaluation

2. Décret $n^{\circ}$ 2012-1116 du 2 octobre 2012 relatif aux missions médicoéconomiques de la Haute Autorité de santé. 2012-1116 Oct 2, 2012.

3. Department of Economics and Public Health. Choices in Methods for Economic Evaluation [Internet]. HAS; 2012 Oct [cited 2018 Feb 9]. Available from: https://www.has-sante.fr/portail/upload/docs/application/pdf/2012-10/ choices in methods for economic evaluation.pdf

4. Hoefman RJ, van Exel J, Brouwer W. How to include informal Care in Economic Evaluations. PharmacoEconomics. 2013:31(12):1105-19.

5. Koopmanschap MA, van Exel JNA, van den Berg B, Brouwer WBF. An overview of methods and applications to value informal care in economic evaluations of healthcare. PharmacoEconomics. 2008;26(4):269-80.

6. Liu JLY, Maniadakis N, Gray A, Rayner M. The economic burden of coronary heart disease in the UK. Heart. 2002;88(6):597-603.

7. Oliva-Moreno J, Peña-Longobardo LM, Vilaplana-Prieto C. An estimation of the value of informal care provided to dependent people in Spain. Appl Health Econ Health Policy. 2015;13(2):223-31.

8. Oliva-Moreno J. Assessment, Peña-Longobardo LM, Del Pozo-Rubio R. the valuation of informal Care in Cost-of-Illness Studies: a systematic review. PharmacoEconomics. 2017:35(3):331-45.

9. Jönsson L, Wimo A. The cost of dementia in Europe. PharmacoEconomics. 2009;27(5):391-403.

10. Acute Coronary Syndrome: Practice essentials, Background, Etiology. 2018 Sep 5; Available from: https://emedicine.medscape.com/article/1910735overview

11. Gervès-Pinquié $C$, Bellanger MM, Ankri J. Willingness to pay for informal care in France: the value of funding support interventions for caregivers. Health Econ Rev. 2014;4(1):34.

12. Gervès $C$, Bellanger MM, Ankri J. Economic analysis of the intangible impacts of informal care for people with Alzheimer's disease and other mental disorders. Value Health J Int Soc Pharmacoeconomics Outcomes Res. 2013;16(5):745-54.

13. Paraponaris A, Davin B, Verger P. Formal and informal care for disabled elderly living in the community: an appraisal of French care composition and costs. Eur J Health Econ HEPAC Health Econ Prev Care. 2012;13(3):327-36.

14. Bérengère Davin, Alain Paraponaris, Christel Protière. Pas de prix mais un coût ? Évaluation contingente de l'aide informelle apportée aux personnes âgées en perte d'autonomie. Économie et Statistique $n^{\circ}$ 475-476. Insee. 2015.

15. Dujardin J-J, Cambou J-P. Épidémiologie de l'infarctus du myocarde. EMC Cardiol-Angéiologie. 2005;2(4):375-87.
16. Häkkinen U, Chiarello P, Cots F, Peltola M, Rättö H, EuroDRG group. Patient classification and hospital costs of care for acute myocardial infarction in nine European countries. Health Econ. 2012 Suppl 2:19-29.

17. Gabet A, Danchin N, Olié V. Infarctus du myocarde chez les femmes: évolutions des taux d'hospitalisation et de mortalité, France, 2002-2013. Bull Épidémiologique Hebd. 2016 8:(7-8).

18. Levine DA, Davydow DS, Hough CL, Langa KM, Rogers MAM, Iwashyna TJ. Functional disability and cognitive impairment after hospitalization for myocardial infarction and stroke. Circ Cardiovasc Qual Outcomes. 2014;7(6):863-71.

19. Van den Berg B, Brouwer W, van Exel J, Koopmanschap M, van den Bos GAM, Rutten F. Economic valuation of informal care: lessons from the application of the opportunity costs and proxy good methods. Soc Sci Med 1982. 2006;62(4):835-45.

20. Hallberg S, Gandra SR, Fox KM, Mesterton J, Banefelt J, Johansson G, et al. Healthcare costs associated with cardiovascular events in patients with hyperlipidemia or prior cardiovascular events: estimates from Swedish population-based register data. Eur J Health Econ HEPAC Health Econ Prev Care. 2016:17(5):591-601.

21. Handicap-Santé, volet Ménages (HSM) - 2008, INSEE [producteur], ADISP$\mathrm{CMH}$ [diffuseur].

22. Handicap-Santé, volet Aidants informels (HSA) - 2008, DREES - Ministère de la Santé [producteur], ADISP-CMH [diffuseur].

23. Katz Index of Independence in Activities of Daily Living. Geriatr Nur (Lond). 2000 Mar 1;21(2):109.

24. Salaire minimum de croissance (Smic) [Internet]. [cited 2018 Aug 31]. Available from: https://www.service-public.fr/particuliers/vosdroits/F2300

25. Bressé S. L'enjeu de la professionnalisation du secteur de l'aide à domicile en faveur des personnes âgées. Retraite Société. 2003;no 39(2):119-43.

26. Indice des prix à la consommation harmonisé - Base 2015 - Ensemble des ménages - France - Nomenclature Coicop : Ensemble harmonisé INSEE. 2017. https://www.insee.fr/fr/statistiques/serie/001759971 (20 July 2017).

27. Gervès $C$, Chauvin P, Bellanger MM. Evaluation of full costs of care for patients with Alzheimer's disease in France: the predominant role of informal care. Health Policy. 2014;116(1):114-22.

28. Paraponaris A, d' Allessandro E, Davin B, Protière C, Tache G. L'utilisation de l'évaluation contingente pour valoriser l'aide informelle apportée aux personnes souffrant de handicap ou en perte d'autonomie : quelle intelligibilité dans le cadre d'enquêtes en population générale (QUALIMEC) ? [Internet]. Unité Mixte de Recherches 912 INSERM-IRD-Université d'AixMarseille, SE4S : Sciences Economiques et Sociales, Systèmes de Santé, Sociétés; 2012 Juin [cited 2018 Nov 28]. Available from: https://www.cnsa.fr/ documentation/081-paraponaris-rapport final.pdf

29. Garrido-García S, Sánchez-Martínez F-I, Abellán-Perpiñán J-M, van Exel J. Monetary valuation of informal care based on Carers' and Noncarers' preferences. Value Health J Int Soc Pharmacoeconomics Outcomes Res. 2015:18(6):832-40

30. Tessier P. Harsanyi, Sen ou Bentham : quelle perspective adopter pour l'évaluation du bien-être en santé ? Rev Économique. 2009:(2009-11) vol. 60(6):1309-33.

31. Naiditch M. IRDES - Comment pérenniser une ressource en voie de raréfaction ? Enseignements d'une comparaison des politiques d'aide aux aidants des personnes âgées dépendantes en Europe Quest Déconomie Santé. 2012;176.

32. Dubourg WR, Jones-Lee MW, Loomes G. Imprecise preferences and the WTP-WTA disparity. J Risk Uncertain. 1994;9(2):115-33.

33. Klose T. The contingent valuation method in health care. Health Policy. 1999:47(2):97-123.

34. Hanemann M. Willingness to pay and willingness to accept: how much can they differ? Am Econ Rev. 1991:81(3):635-47.

35. Kahneman D, Tversky A. Choices, values, and frames. Am Psychol. 1984; 39(4):341-50.

36. Arrow K, Solow R, Portney PR, Leamer EE. Radner R. Federal Register: Schuman H. Report of the NOAA Panel on contingent Valuation; 1993. p. 4602-14.

37. Puymirat E, Simon T, Steg PG, Schiele F, Guéret P, Blanchard D, et al. Association of changes in clinical characteristics and management with improvement in survival among patients with ST-elevation myocardial infarction. JAMA. 2012;308(10):998-1006. 
38. Krol M, Papenburg J, van Exel J. Does including informal care in economic evaluations matter? A systematic review of inclusion and impact of informal care in cost-effectiveness studies. PharmacoEconomics. 2015;33(2):123-35.

39. Peña-Longobardo LM, Rodríguez-Sánchez B, Oliva-Moreno J, Aranda-Reneo I, López-Bastida J. How relevant are social costs in economic evaluations? The case of Alzheimer's disease. Eur J Health Econ [Internet]. 2019; Available from: https://doi.org/10.1007/s10198-019-01087-6.

\section{Publisher's Note}

Springer Nature remains neutral with regard to jurisdictional claims in published maps and institutional affiliations.

Ready to submit your research? Choose BMC and benefit from:

- fast, convenient online submission

- thorough peer review by experienced researchers in your field

- rapid publication on acceptance

- support for research data, including large and complex data types

- gold Open Access which fosters wider collaboration and increased citations

- maximum visibility for your research: over $100 \mathrm{M}$ website views per year

At $\mathrm{BMC}$, research is always in progress.

Learn more biomedcentral.com/submissions 